\title{
Eosinophilia, Pleural Effusion, Hepatitis, and Jaundice Occurring Early in Clozapine Treatment
}

\author{
Shi Hyun Kang, Jong-II Lee \\ Department of Psychiatry, Seoul National Hospital, Seoul, Korea
}

Clozapine use is associated with various adverse events, some of which have received little attention, including eosinophilia, pleural effusion, and hepatitis. Because of the fatality of jaundice with hepatitis, it is necessary to understand the course and management of clozapine-induced eosinophilia and hepatitis. We report on a case in which the eosinophil count began to increase shortly after clozapine use, and pleural effusion and fever then developed at the time eosinophilia was at its peak level. Jaundice with hepatitis consecutively developed when all the above symptoms subsided. The liver function recovered rapidly after clozapine was discontinued. We recommend that patients who develop rapid eosinophilia at the beginning of clozapine treatment should be monitored with LFTs, chest X-rays, and urine analysis tests.

KEY WORDS: Clozapine; Eosinophilia; Hepatitis; Jaundice; Pleural effusion.

\section{INTRODUCTION}

Clozapine use is associated with various adverse events. ${ }^{1)}$ The associations of eosinophilia, hepatitis, and pleural effusion with clozapine have received little attention because these conditions are considered to be rare or not life-threatening side effects.

The incidence of eosinophilia associated with clozapine has been reported to range from $0.2 \%$ to $62 \%{ }^{2}{ }^{2}$ Eosinophilia usually develops during the initial phase, between weeks 3 and 5 of clozapine use, and follows a transient course characterized by spontaneous remission. However, eosinophilia has been associated with major organ involvement such as hepatitis. ${ }^{3)}$

Elevation of liver enzymes secondary to clozapine use is common and affects $30-50 \%$ of patients. ${ }^{4}$ It is usually transient and detected accidentally. The onset of liver toxicity is usually 4-5 weeks after initiating clozapine therapy. ${ }^{4)}$ However, a few patients with clozapine-induced jaundice were reported to have died as a result of fulminant hepatic failure. ${ }^{5-7)}$

It is necessary to understand the course and manage-

Received: February 19, 2013 / Accepted: March 25, 2013

Address for correspondence: Shi Hyun Kang, MD, PhD

Department of Psychiatry, Seoul National Hospital, 398 Neungdong-ro, Gwangiin-gu, Seoul 143-711, Korea

Tel: +82-2-2204-0326, Fax: +82-2-2204-0394

E-mail: drshe@hanmail.net ment of clozapine-induced eosinophilia and hepatitis. We discuss a patient who developed eosinophilia at the beginning of clozapine use and then successively developed pleural effusion and jaundice with hepatitis.

\section{CASE}

Ms. A, a 47-year old woman with a 15-year history of schizophrenia, was hospitalized after noncompliance with antipsychotic medications, which resulted in decompensation characterized by aggressive behavior, auditory hallucinations and delusions. All laboratory tests performed on admission, including complete blood cell count (CBC), serum electrolytes, urinalysis, and liver function tests (LFTs), were within normal limits. Hepatitis serology revealed that the hepatitis B surface (HBs) antibody was positive and that the HBs antigen was negative. Ms. A was a non-smoker and non-drinker with no history of substance misuse and no significant medical history.

Due to poor responses to previous antipsychotic treatments, the patient was started on clozapine with the dose titrated from $12.5 \mathrm{mg} /$ day to $300 \mathrm{mg}$ /day during a 4-week period. During this period the patient had no other medications.

The weekly checks of the CBC showed gradual increases in the eosinophil count following the beginning of clozapine treatment. The eosinophil count was $0.9 \%$

(c) This is an Open-Access article distributed under the terms of the Creative Commons Attribution Non-Commercial License (http://creativecommons.org/licenses/by-nc/3.0) which permits unrestricted non-commercial use, distribution, and reproduction in any medium, provided the original work is properly cited. 
$\left(57 / \mathrm{mm}^{3}\right)$ before clozapine use, $1.7 \%\left(142 / \mathrm{mm}^{3}\right)$ at day 8 , $2.8 \%\left(248 / \mathrm{mm}^{3}\right)$ at day 15 , and $5.0 \%\left(416 / \mathrm{mm}^{3}\right)$ at day 22 . On day 29, the total leukocyte count increased to $10,910 / \mathrm{mm}^{3}$, and the eosinophilia reached $23.6 \%$ $\left(2,575 / \mathrm{mm}^{3}\right)$. Ms. A did not have any symptoms.

On day 35 , the patient complained of general myalgia and $37.5^{\circ} \mathrm{C}$ fever. Both leukocytosis $\left(16,500 / \mathrm{mm}^{3}\right)$ and eosinophilia $\left(28.9 \%, 4,769 / \mathrm{mm}^{3}\right)$ were aggravated. A chest X-ray revealed some amount of right side pleural effusion. The pleural effusion was considered to be the cause of the fever and leukocytosis, and conservative management of oral antibiotics was provided. Because clozapine was effective in managing the psychotic symptoms, it was maintained at the reduced dosage of 100 $\mathrm{mg}$ /day. On day 42, the total leukocyte count was normalized, at $9,230 / \mathrm{mm}^{3}$ but the eosinophil count had increased to $54.2 \%\left(5,003 / \mathrm{mm}^{3}\right)$. She showed an intermittent $37.7^{\circ} \mathrm{C}$ fever, but general myalgia had disappeared. On day 44 , a repeat chest X-ray revealed that the pleural effusion had nearly disappeared, and the fever had subsided. The total leukocyte and eosinophil count decreased to $8,350 / \mathrm{mm}^{3}$ and $40.1 \%\left(3,348 / \mathrm{mm}^{3}\right)$, respectively.

On day 48 , the patient suddenly became jaundiced, and she was transferred to the department of internal medicine at a general hospital. The total leukocyte count was $3,600 / \mathrm{mm}^{3}$ with $12.9 \%\left(464 / \mathrm{mm}^{3}\right)$ eosinophil. The LFTs were notable for the following abnormalities: alanine transaminase (ALT) $254 \mathrm{IU} / \mathrm{L}$ (range, 4-43), aspartate transaminase (AST) 277 IU/L (range, 7-38), r-glutamyltransferase (GGT) $573 \mathrm{U} / \mathrm{L}$ (range, 8-48), total bilirubin $6.0 \mathrm{mg} / \mathrm{dl}$ (range, 0.2-1.2), and direct bilirubin $3.5 \mathrm{mg} / \mathrm{dl}$ (range, 0.1-0.4). Abdominal computed tomography showed hepatopathy by acute hepatitis. The urinalysis showed urobilinogen 2+ (range, trace). The patient retrospectively reported that her urine color had changed to red during the previous 2 weeks.

After 5 days without clozapine, the LFTs improved, showing an ALT level of $22 \mathrm{IU} / \mathrm{L}$, an AST level of 37 IU/L, a GGT level of $46 \mathrm{U} / \mathrm{L}$, a total bilirubin of $0.6 \mathrm{mg} / \mathrm{dl}$, and a direct bilirubin of $0.2 \mathrm{mg} / \mathrm{dl}$. The total leukocyte count was $4,200 / \mathrm{mm}^{3}$ with $10.5 \%\left(441 / \mathrm{mm}^{3}\right)$ eosinophil. Ms. A was readmitted to our hospital after 1 week without clozapine for treatment of psychotic symptoms. The total leukocyte count was $4,400 / \mathrm{mm}^{3}$ with $3.4 \%\left(150 / \mathrm{mm}^{3}\right)$ eosinophil on the day of readmission. There were no recurrences of LFT or CBC abnormalities during following treatment with olanzapine and haloperidol.

\section{DISCUSSION}

In this case, the eosinophil count began to increase shortly after clozapine use and reached its peak level at week 5-6, and since then, the eosinophil count gradually decreased. Pleural effusion and red colored urine developed at week 5 and jaundice developed around at week 7 when the eosinophilia was nearly disappeared.

Benign eosinophilia is peripheral eosinophilia noted shortly after clozapine administration without other evidence of inflammatory processes. Some patients with eosinophilia have experienced inflammation of major organs such as pancreatitis ${ }^{8)}$ and a few cases with more severe forms of multi-organ involvement have been reported. ${ }^{9,10)}$

In cases in which eosinophilia is accompanied by the involvement of major organs, clozapine should be discontinued immediately. On the other hand, it does not seem necessary to discontinue clozapine if benign eosinophilia develops. The Sandoz guidelines ${ }^{11)}$ recommend that clozapine be discontinued when eosinophil counts exceed $4,000 / \mathrm{mm}^{3}$, and that it not be resumed until they are lower than $3,000 / \mathrm{mm}^{3}$.

Several previous reports have shown that clozapine-induced hepatitis frequently accompanies eosinophilia. However, none of the three fatal cases of hepatic failure found comorbid eosinophilia. ${ }^{5-7)}$ Considering our case, it is possible that fulminant hepatitis including jaundice may develop after eosinophilia subsides. That is, the timing of abnormal LFTs may coincide with eosinophilia. Additional monitoring of eosinophil during mandatory weekly leukocyte follow-up visits may be helpful for detecting LFT elevations during early stage.

The Sandoz guidelines indicate that clozapine should be discontinued if any LFT increases which is clinically relevant or if symptoms of jaundice occurs. After normalization of LFTs, some patients were able to restart clozapine, ${ }^{11)}$ but some were not able to do so. ${ }^{12)}$ Most patients who developed jaundice did not restart clozapine.

Associations between clozapine and pleural disease are rare. Pleural effusions associated with clozapine have usually been associated with other systemic manifestations such as pericardial effusion. ${ }^{13)}$

In our case, pleural effusion was accompanied by fever and leukocytosis and subsided after antibiotic therapy; thus, parapneumonic effusion is probable. However, redcolored urine, fever, pleural effusion, and the peak eosinophil count were observed at around the same time. Some reports have described multi-organ idiosyncratic re- 
sponses to clozapine, such as eosinophilia, pleural effusion, hepatitis, cholecystitis, ascitis, and hematuria during clozapine use. $^{9-10)}$

Therefore, we recommend that patients who develop rapid eosinophilia at the beginning of clozapine treatment should be monitored with LFTs, chest X-rays, and urine analysis tests.

\section{REFERENCES}

1. Alphs LD, Meltzer HY, Bastani B, Ramirez LF. Side effects of clozapine and their management. Pharmacopsychitary 1991;24:46.

2. Sadock BJ, Sadock VA, Ruiz P. Kaplan \& Sadock's comprehensive textbook of psychiatry. 9th ed. Philadelphia:Wolters Kluwer/Lippincott Williams \& Wilkins;2009. p.32063241.

3. Kellner M, Wiedemann K, Krieg JC, Berg PA. Toxic hepatitis by clozapine treatment. Am J Psychiatry 1993;150: 985-986.

4. Hummer M, Kurz M, Kurzthaler I, Oberbauer H, Miller C, Fleischhacker WW. Hepatotoxicity of clozapine. J Clin Psychopharmacol 1997;17:314-317.

5. Macfarlane B, Davies S, Mannan K, Sarsam R, Pariente D, Dooley J. Fatal acute fulminant liver failure due to clozapine: a case report and review of clozapine-induced hepatotoxicity. Gastroenterology 1997;112:1707-1709.
6. Chang A, Krygier DS, Chatur N, Yoshida EM. Clozapine-induced fatal fulminant hepatic failure: a case report. Can J Gastroenterol 2009;23:376-378.

7. Chaplin AC, Curley MA, Wanless IR. Re: Recent case report of clozapine-induced acute hepatic failure. Can J Gastroenterol 2010;24:739-740.

8. Bergemann N, Ehrig C, Diebold K, Mundt C, von Einsiedel R. Asymptomatic pancreatitis associated with clozapine. Pharmacopsychiatry 1999;32:78-80.

9. Thompson J, Chengappa KN, Good CB, Baker RW, Kiewe RP, Bezner J, et al. Hepatitis, hyperglycemia, pleural effusion, eosinophilia, hematuria and proteinuria occurring early in clozapine treatment. Int Clin Psychopharmacol 1998;13: 95-98.

10. Hong HJ, Kim CH, Song DH, Lee SJ, Lee HS. A case of clozapine-induced eosinophilia combined with bilateral pleural effusion, ascites, cholecysctitis, and hepatitis. Korean $J$ Psychopharmacol 1999;10:191-195.

11. Jang SJ, Yi HT, Paek JH, Lee SY. Clozapine-induced acute hepatitis. J Korean Neuropsychiatr Assoc 1999;38:227-233.

12. Keane S, Lane A, Larkin T, Clarke M. Management of clozapine-related hepatotoxicity. J Clin Psychopharmacol 2009;29:606-607.

13. Jung SH, Kim WH, Choi HJ, Lee MJ, Kang MH, Kim CE, et al. Pericarditis with pericardial effusion and bilateral pleural effusion associated with clozapine treatment in an adolescent boy. Korean J Psychopharmacol 2009;20:141146. 